\title{
Oxygen pitting failure of a bagasse boiler tube
}

\author{
A.M. Heyes \\ Advanced Engineering and Testing Services, MATTEK, CSIR, Private Bag X28, Auckland Park, 2006, South Africa
}

Received 1 June 1999; accepted 26 October 1999

\begin{abstract}
Examination of a failed roof tube from a bagasse boiler showed transverse through-cracks and extensive pitting. The pitting was typically an oxygen induced pitting and numerous fatigue cracks had started within these pits. It is highly probable that the pitting occurred during an idle period (a drought) due to oxygen ingress and failure to maintain a sufficient excess of the oxygen scavenger, sodium sulfite. The transverse orientation of the cracks and other factors suggest that the fatigue cracking is related to tube vibrations. (C) 2001 Elsevier Science Ltd. All rights reserved.
\end{abstract}

Keywords: Boiler failure; Corrosion; Fatigue failure; Pitting corrosion; Vibration

\section{Introduction}

A bagasse (sugar cane waste) boiler was re-commissioned after standing idle for 'several' months during a period of drought. A roof tube failed approximately one year after this and three samples of this tube were submitted for examination. It was reported that a leak had occurred previously in the same tube, near a tube support which had been welded on. The operators of the boiler attributed the first failure to undercutting of the weld (causing a stress concentration), but could find no evident cause for the subsequent failures, which were away from the weld and on the fireside of the tube.

The boiler, a schematic of which is given in Fig. 1, has a design pressure of 35 bar (500 psi), a design temperature of $293^{\circ} \mathrm{C}\left(560^{\circ} \mathrm{F}\right)$, and a capability of generating $40,800 \mathrm{~kg}(90,000 \mathrm{lb})$ of steam per hour. Feed water is supplied from a deaerator station and the water is treated with sodium sulfite to scavenge any remaining oxygen. Boiler water chemistry records for the week prior to the boiler being taken offline were made available by the operators and showed the water chemistry to be acceptable.

According to the information supplied, the drought storage procedure involved storing the boiler wet for a period of 'several' months after which the boiler was drained and dried out by means of a hot air

E-mail address: aheyes@csir.co.za (A.M. Heyes). 
blower. Trays of lime were placed in the steam drum to act as a desiccant, but were replaced shortly thereafter with a vapour phase inhibitor.

The boiler had also been re-tubed with BS3059/2 ERW 360 tubes approximately 4 years prior to the failure. The previous tube set had lasted for 20 years, making this failure somewhat unexpected.

\section{Optical examination}

\subsection{Visual examination}

Three samples were received: one comprising the two halves of the tube from the main point of leakage and another half section of the tube, where leakage was only slight. The external (fireside and rearside) and internal surfaces of the samples are shown in Figs. 2 and 3, respectively. Visual examination suggested that there were two through-cracks and that they had originated on the internal surface of the tube, as evidenced by the pitting and transverse cracking shown in Figs. 4 and 5. The internal surface of the tube was covered by an adherent magnetite scale with many of the pitted areas showing red rusting. Fireside deposits were minimal and little deterioration of the external tube surfaces was evident. However, there was a clear difference in the appearance of the fireside and rearside external surfaces, explained by the fact that the roof tubes are recessed into the roof tiles to a depth of half their

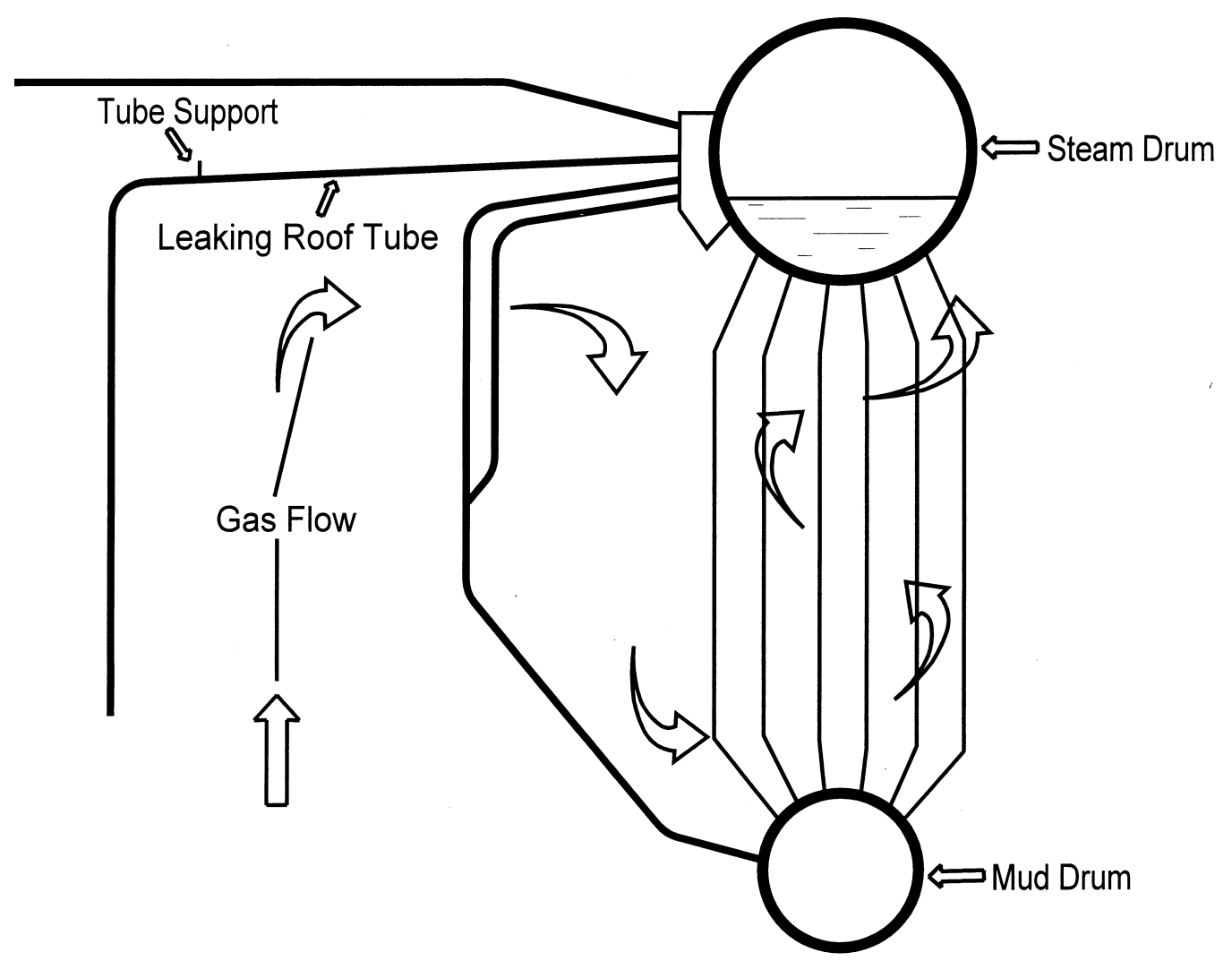

Fig. 1. Schematic showing the arrangement of the boiler. 
diameter. Both of the failures appeared to have occurred on the lower half (fireside) of the tubes and this was confirmed by the operator. On close examination it could be seen that almost all of the pitting and cracking was on the lower half of the tubes.

\subsection{Stereo microscope examination}

The pitted surfaces were examined under a stereo microscope at magnifications up to $65 \times$. Many small pits, with transverse cracks originating from them, were visible. These surfaces are shown in Figs. 6 and 7, where the large through-crack and small through-crack are visible. The morphology of the pitting is consistent with that of oxygen pitting [1-3].

Oxygen pitting is a phenomenon which occurs in boiler waters when the dissolved oxygen content increases [1,2]. It is also often associated with a concurrent decrease in $\mathrm{pH}$ [1]. Under such conditions the type of oxide formed by the corrosive process changes and small areas of haematite $\left(\mathrm{Fe}_{2} \mathrm{O}_{3}\right)$ are formed at weak points in the magnetite $\left(\mathrm{Fe}_{3} \mathrm{O}_{4}\right)$ layer. As hydrated $\mathrm{Fe}_{2} \mathrm{O}_{3}$ may be removed from the tube surface, especially in non-alkaline waters, small areas of the tube surface are exposed. These

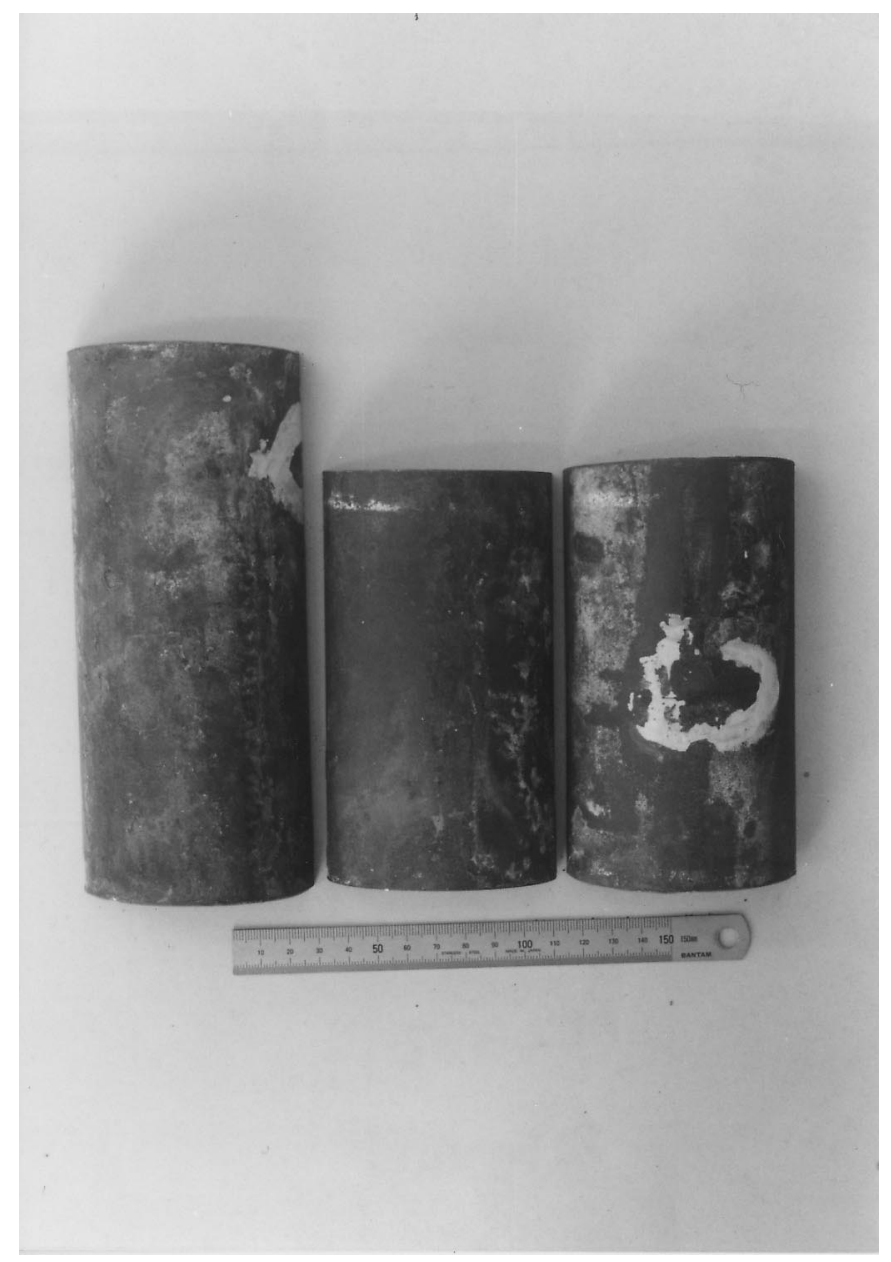

Fig. 2. External surfaces of the tube samples supplied. 
exposed areas are then preferentially attacked, while the majority of the surface is sacrificially protected by the anodic dissolution occurring inside the pits, i.e. the remaining magnetite layer acts as a large cathode while the bare areas act as small anodes [4]. A large cathode to anode area ratio is unfavourable as the high corrosion current density at the anodic sites leads to rapid metal dissolution [3]. The net result is pitting in the areas where breakdown of the magnetite film has occurred.

While oxygen pitting explains the presence of pits in the tube and is not an uncommon occurrence in boilers which have been off-line for some time, it cannot explain the observed cracking. Therefore, the cracks were examined with the aid of a Scanning Electron Microscope (SEM).

\section{Electron microscopy}

Examination of the pitted areas showed a majority of cracks to have started at pits, this being a result of the stress concentration formed by the pit. A clear example of this is shown in Fig. 8. Small, isolated cracks were found to have initiated in areas where no pits were present, but these were not responsible

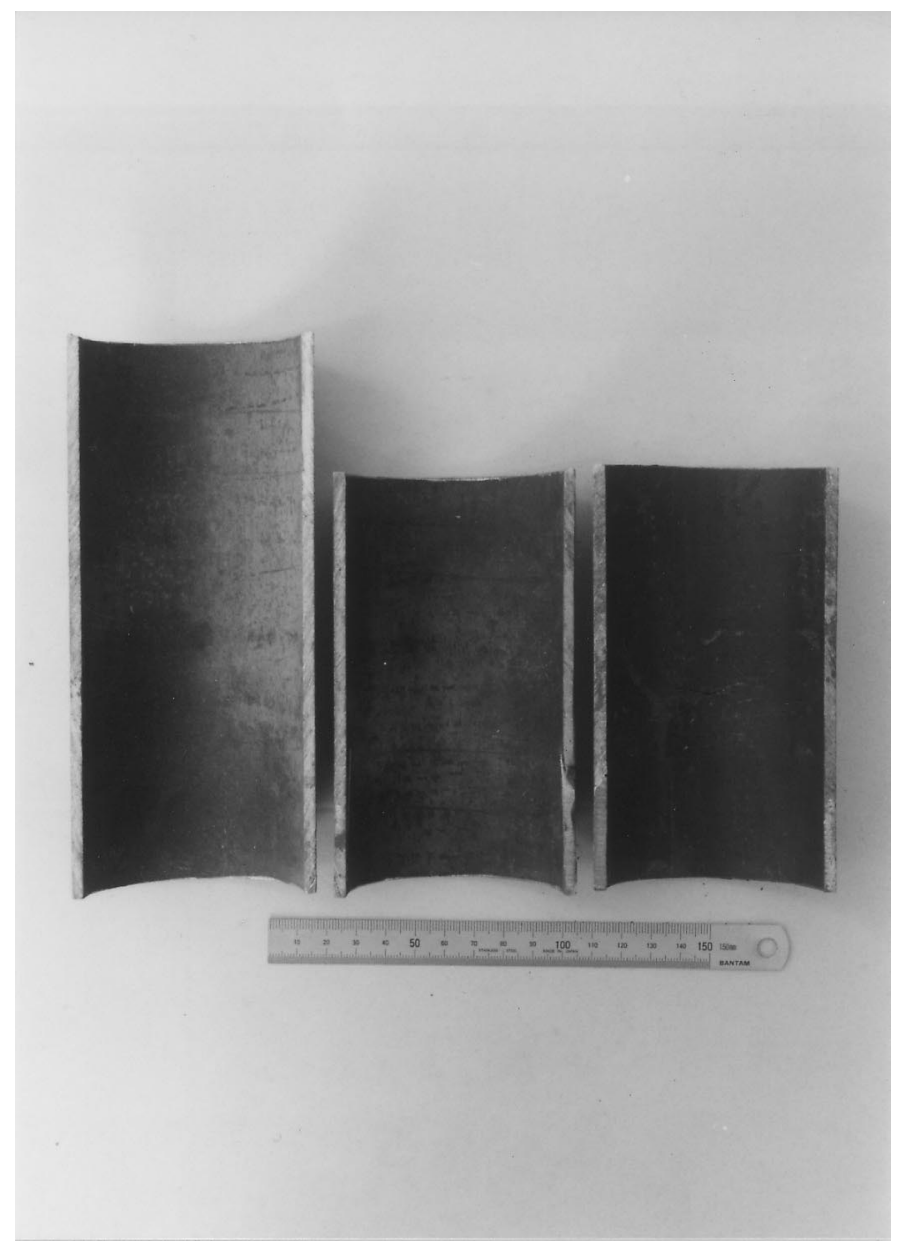

Fig. 3. Internal surfaces of the tube samples. 


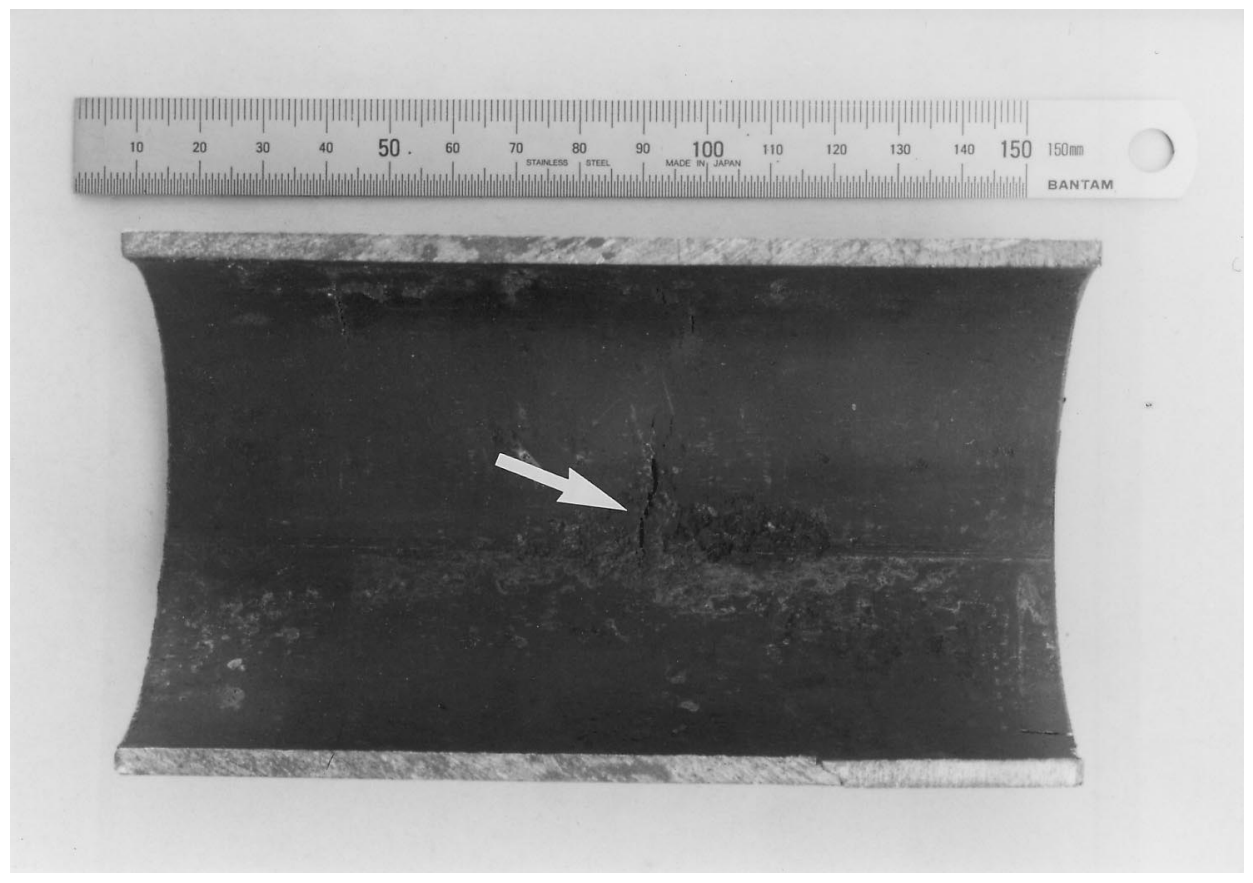

Fig. 4. Pitting and cracking (arrowed) visible in area of major leakage.

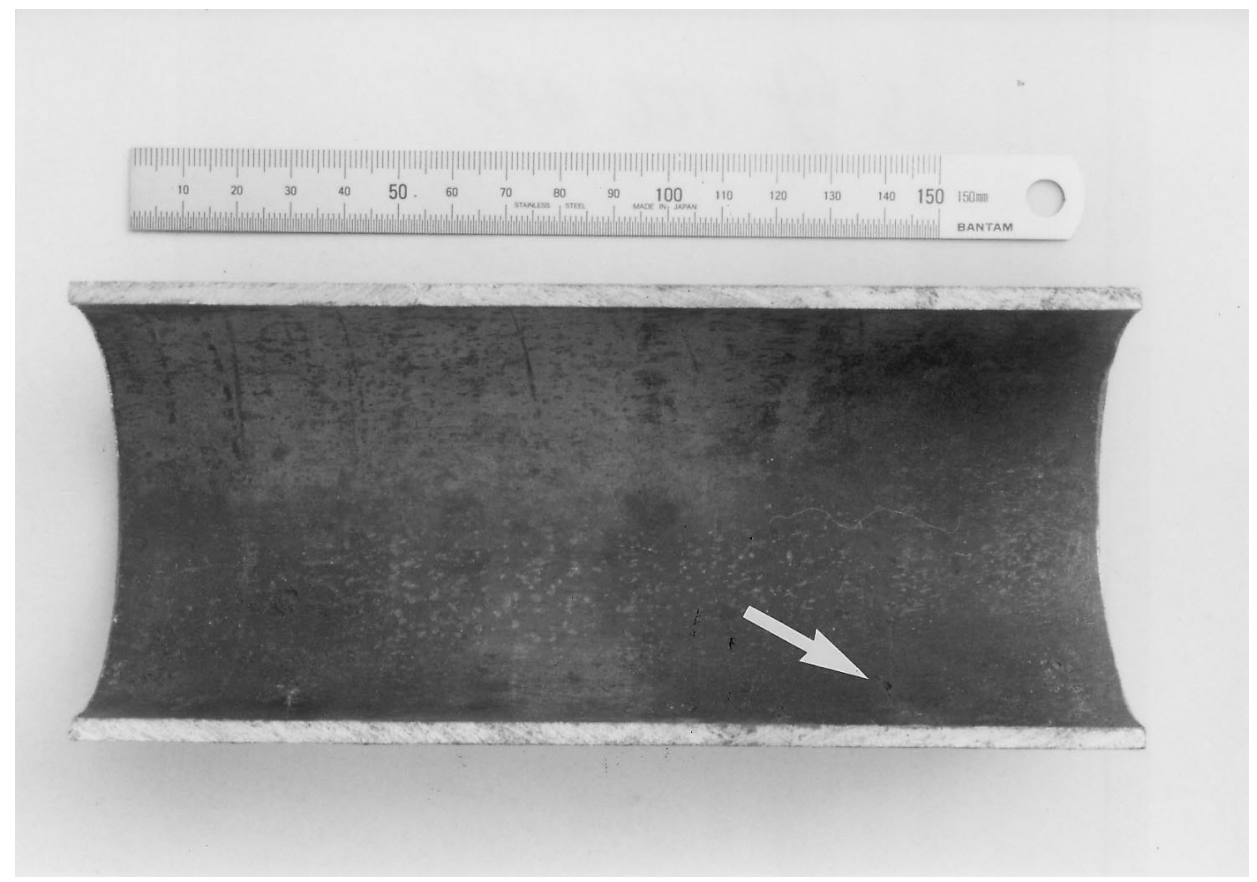

Fig. 5. Pitting and cracking (arrowed) at site of minor leakage. 


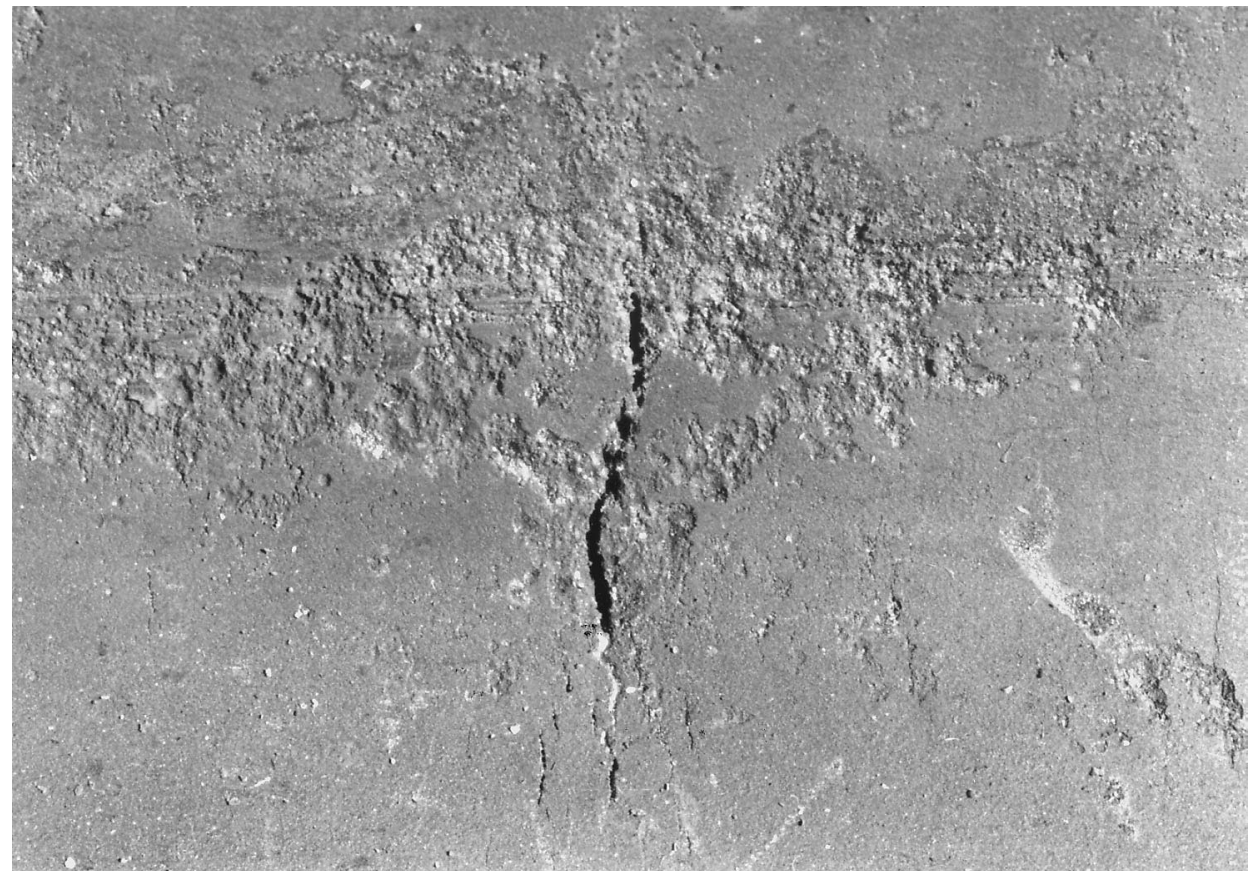

Fig. 6. Close up view of the crack at the point of major leakage.

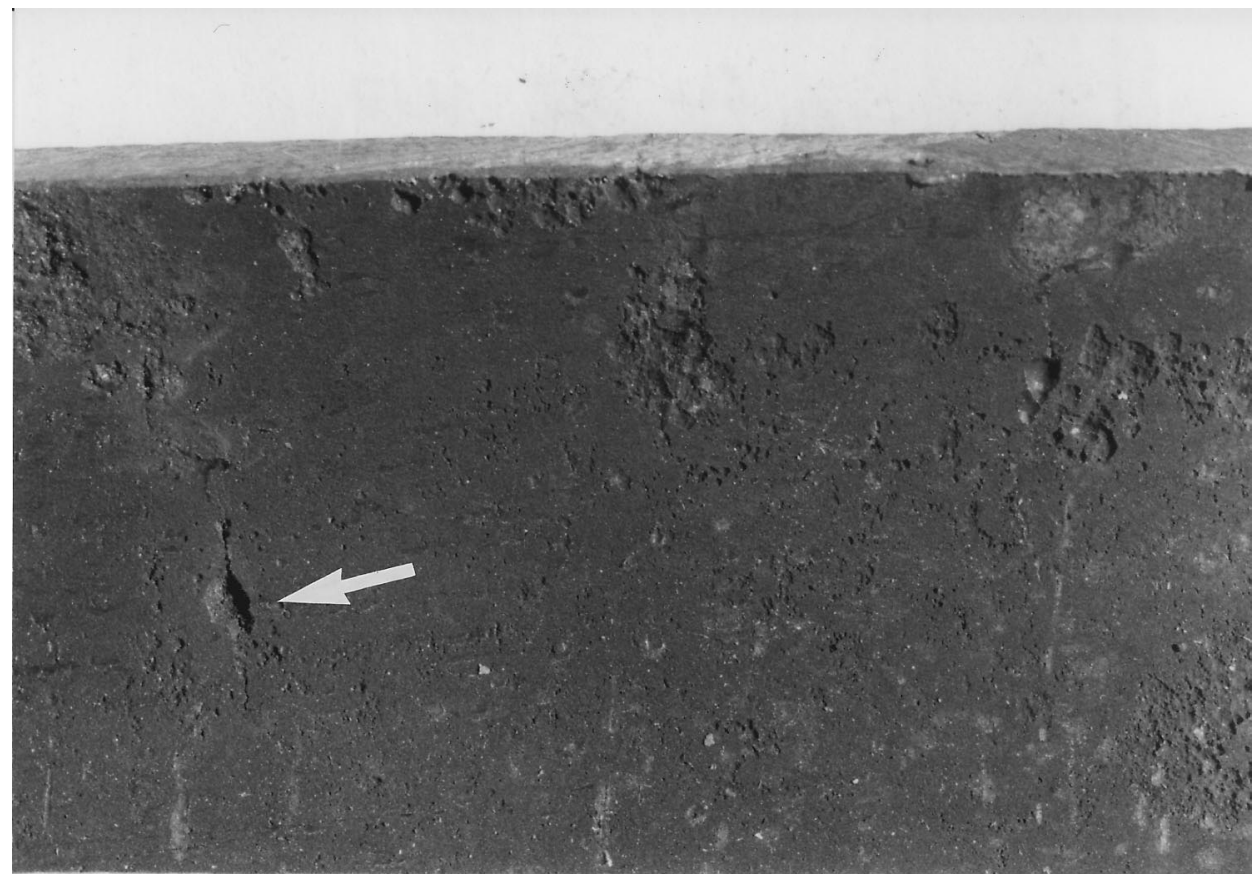

Fig. 7. Close up view of the crack (arrowed) and pitting at the point of minor leakage. 
for any of the leakages experienced. However, this does suggest that the through-cracking would have eventually occurred regardless of whether or not the stress concentrating pits were present.

The fracture surface of the main crack was exposed, and an examination under the SEM clearly shows the cracking mechanism to be that of fatigue, as evidenced by the breach markings present on the fracture surface (Fig. 9). It can be seen that the fatigue has, as expected, originated from one of the many pits.

The origin of the cyclic stresses causing the fatigue to occur can be deduced from the operating conditions and orientation and location of the cracks:

(i) Pressure variations cause cyclic loads, but would cause longitudinal cracking (due to the hoop stress) which was not observed. Therefore, this is unlikely to be the cause.

(ii) Thermal cycling from effects such as water splash would result in a network of surface cracks, which was not observed. Therefore, this is unlikely to be the cause.

(iii) Thermal stresses are induced, every time a boiler is fired or shutdown. However, in this case the boiler operated on a continuous basis when in use. Therefore, the number of stress cycles experienced from startups and shutdowns would have been too few to account for the observed cracks.

(iv) Cyclic thermal stresses could be created by restraint of the tube and unstable fireside temperatures, but the configuration of the tube makes sufficient restraint unlikely.

(v) Vibration of the tubes can cause high cycle fatigue. The cracks were located on the bottom of the tube, the side of the tube which would experience cyclic tensile loads. This is due to the weight of the tube, which would place the bottom of the tube in tension. Vibrations can also explain the cracking at the tube support.

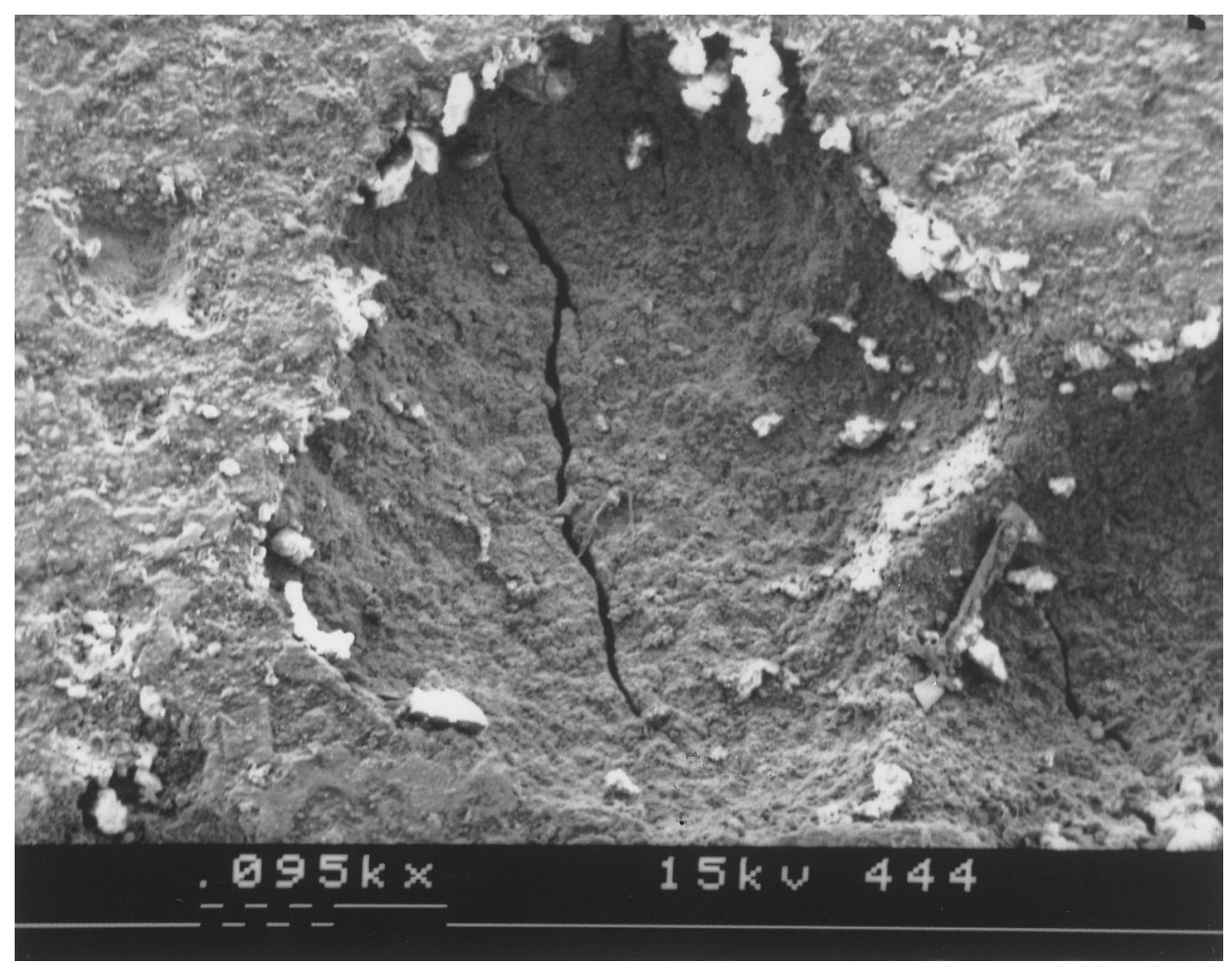

Fig. 8. A fatigue crack initiated at the bottom of a pit. 
It is therefore most likely that the fatigue was caused by vibration of the tube, usually a result of a harmonic oscillation being set up.

\section{Conclusions and recommendations}

The pitting observed in the tube was a result of oxygen pitting and probably occurred during the wet storage period due to inadequate maintenance of the water levels, $\mathrm{pH}$ and the amount of oxygen scavenger. During wet storage the boiler should have been kept completely filled with water (to exclude air) or nitrogen capped, the $\mathrm{pH}$ maintained around 11 and the water dosed with a sodium sulfite to a residual level of at least $100 \mathrm{ppm}$ [5]. Higher levels $(250 \mathrm{ppm})$ are recommended for longer periods of wet lay-up [6]. Regular checks on these parameters are mandatory. Also, wet storage is generally taken to be permissible for periods of less than one month, after which dry storage procedures should be implemented [3]. The correlation between tube leaks and failures and incorrect standby corrosion protection practice has been observed on many occasions [3].

The most likely cause of the cracking observed in the tube is vibrations caused by a harmonic oscillation. Obviously, the vibrations must be minimised or eliminated, if possible, either by changes in boiler operation or by changes to the support of the tubes. As it was very likely that other tubes (and possibly the steam drum) would have suffered damage, a thorough NDT examination was recommended.

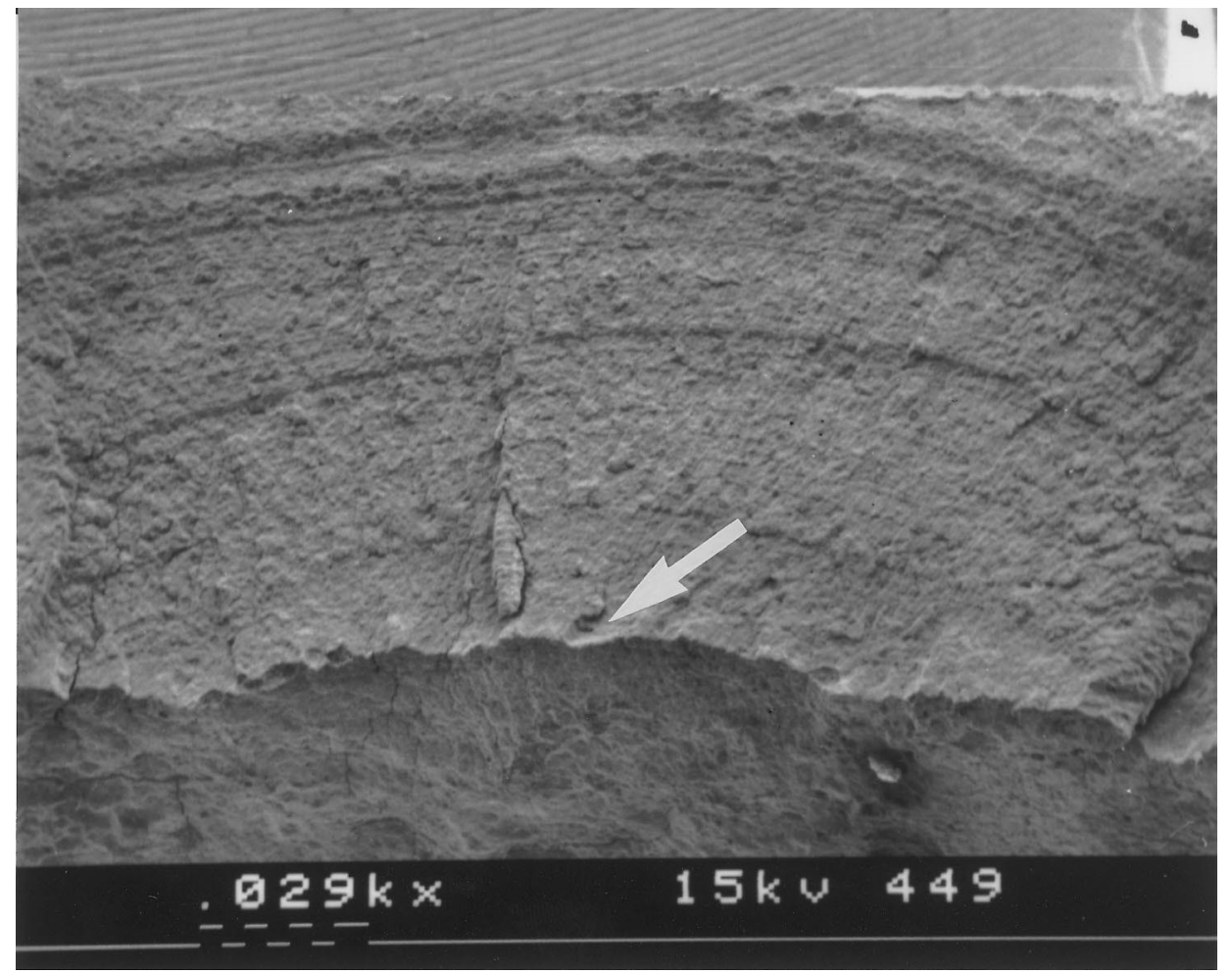

Fig. 9. Fatigue beach marks present on major fracture surface. Note that the origin of the fatigue crack is a pit (arrowed). 


\section{References}

[1] French DN. Metallurgical failures in fossil fired boilers, 2nd ed. New York: Wiley, 1993. p. 326-30, 386-94.

[2] American Society for Metals. Metals handbook, vol. 11: Failure analysis and prevention, 9th ed. 1986 , p. 602-27.

[3] Herro HM, Port RD. The Nalco guide to cooling water system failure analysis. New York: McGraw-Hill, 1993 . p. 97-118.

[4] American Society for Metals. Metals handbook, vol. 13: corrosion, 9th ed. 1987, p. 84.

[5] Drew Industrial Division. Principles of Industrial Water Treatment, 11th ed. 1994, p. $214-41$.

[6] Coombs P, Funke JW. CSIR Guide K15: A guide to water treatment in low-pressure and medium pressure boilers. CSIR, 1970. p. 19. 